\title{
Secreted protein acidic and rich in cysteine antagonizes bufalin-induced apoptosis in gastric cancer cells
}

\author{
AODI LI, XIUJUAN QU, ZHI LI, JINGLEI QU, NA SONG, YANJU MA and YUNPENG LIU \\ Department of Medical Oncology, The First Hospital of China Medical University, Shenyang, Liaoning 110001, P.R. China
}

Received January 15, 2014; Accepted August 14, 2014

DOI: $10.3892 / \mathrm{mmr} .2015 .3676$

\begin{abstract}
Bufalin is an active compound in the traditional Chinese medicine Chan $\mathrm{Su}$, which has been shown to induce apoptosis in a range of cancer cell types. However, certain gastric cancer cells are known to be resistant to bufalin. Intracellular secreted protein acidic and rich in cysteine (SPARC) regulates proliferation and apoptosis. This study aimed to evaluate the role of SPARC in bufalin-induced apoptosis in SGC7901 and MGC803 gastric cancer cells. SGC7901 cells with high SPARC expression were more resistant to bufalin than MGC803 cells with low SPARC expression. This resistance was significantly reversed by small interfering (si)RNA-mediated knockdown of SPARC. Furthermore, it was shown that SPARC negatively regulated bufalin-induced intrinsic apoptosis by protecting mitochondrial integrity, decreasing the release of cytoplasmic cytochrome $c$ and increasing the ratio of $\mathrm{Bcl}-2 / \mathrm{Bax}$. In addition, SPARC overcame bufalin-induced G2/M phase arrest by increasing levels of Cyclin B1 and Cyclin A protein expression. SPARC also activated cellular survival signals, including Src and Akt, but not extracellular signal-regulated kinase. This study demonstrated that SPARC antagonizes bufalin-induced apoptosis via inhibition of the intrinsic apoptosis pathway, inhibition of cell cycle arrest and activation of certain pathways involved in proliferation. This provides novel evidence for SPARC as a potential target by which to sensitize gastric cancer cells to bufalin.
\end{abstract}

\section{Introduction}

Gastric cancer is one of the leading causes of cancer-related mortality worldwide (1). The present therapeutic options of chemotherapy and targeted drug treatment are unsatisfactory in the treatment of patients with advanced gastric cancer and

Correspondence to: Professor Yunpeng Liu, Department of Medical Oncology, The First Hospital of China Medical University, 155 North Nanjing Street, Shenyang, Liaoning 110001, P.R. China E-mail: cmuliuyunpeng@hotmail.com; qu_xiujuan@hotmail.com

Key words: secreted protein acidic and rich in cysteine, bufalin, apoptosis, gastric cancer the development of more efficacious and individualized therapies remains a major challenge to be overcome.

The traditional Chinese medicine Chan $\mathrm{Su}$, which is isolated from secretions of the skin and parotid venom glands of the Chinese and black-spectacled toads, contains the active component bufalin (2,3). Previous studies have demonstrated that bufalin exhibits significant antitumor activity, via the induction of apoptosis and inhibition of proliferation, in a number of tumor types, including lung cancer, breast cancer, hepatic carcinoma and leukemia. In these cancer types, inhibition of the phosphoinositide 3-kinase (PI3K)/Akt pathway activation was found to be the predominant mechanism by which bufalin induced apoptosis (4-10). In accordance with this, a previous study from this laboratory found that downregulation of $\mathrm{Bcl} / \mathrm{Bax}$, activation of Caspase-3 and inhibition of the PI3K/Akt signaling pathway occurred during bufalin-induced apoptosis in gastric cancer (11). However, it was shown that not all gastric cancer cells were sensitive to bufalin, suggesting that other factors may have an antagonistic effect on bufalin-induced apoptosis.

Secreted protein acidic and rich in cysteine (SPARC) is a protein that is associated with embryonic development, remodeling, cell turnover and tissue repair (12). SPARC is normally secreted by stromal cells but is also produced by cancer cells, including in pancreatic, breast, prostate and gastric cancer (13-16). Recent studies have reported a positive correlation between overexpression of stromal-derived SPARC and the response to nanoparticle albumin-bound (NAB) drugs in certain tumors. Phase II and III studies have revealed that NAB-paclitaxel was significantly more effective and well-tolerated than conventional docetaxel and paclitaxel in patients with metastatic breast cancer and advanced pancreatic cancer. This increased efficacy is likely to be a result of stromal SPARC directly increasing accumulation of NAB-paclitaxel in tumor tissues via binding to albumin (17-20). However, recent studies have suggested that intracellular SPARC is also important in the regulation of apoptosis and cell proliferation (21-24). Silencing of SPARC expression significantly suppresses tumor cell proliferation and induces apoptosis via modulation of the expression of Bcl-2, Bax and proliferating cell nuclear antigen in human ovarian cancer, melanoma and leukemia $(22,25,26)$. As a number of the apoptosis-related proteins regulated by SPARC are also involved in bufalin-induced apoptosis, the present study investigated the possibility that SPARC may regulate bufalin-induced apoptosis in gastric cancer cells. 


\section{Materials and methods}

Reagents and antibodies. Rabbit anti-Caspase-3 (cat. no. sc-7148; 1:500), anti-Bax (cat. no. sc-493; 1:1,000), anti-Src (cat. no. sc-8995; 1:1,000), anti-cyclin-dependent kinase (cdk)2 (cat. no. sc-748; 1:500), anti-Cyclin B1 (cat. no. sc-752; 1:1,000), anti-Cyclin A (cat. no. sc-596; 1:500), anti-Cyclin E (cat. no. sc-481; 1:1,000) and anti-actin (cat. no. sc-7210, 1:2,000) polyclonal antibodies were obtained from Santa Cruz Biotechnology, Inc. (Santa Cruz, CA, USA). Rabbit anti-Akt (cat. no. 4691; 1:1,000), anti-phospho-(p)Akt (cat. no. 4058; 1:1,000), anti-extracellular signal-regulated kinase (ERK; cat. no. 4348; 1:1,000) anti-phospho-ERK (cat. no. 4370; 1:2,000), anti-phospho-Src (cat. no. 12432; 1:1,000), anti-poly(ADP-ribose) polymerase (PARP; cat. no. 5625, 1:1,000) and anti-Bcl-2 (cat. no. 2870; 1:1,000) monoclonal antibodies were obtained from Cell Signaling Technology (Danvers, MA, USA). A mouse anti-cytochrome $c$ (cat. no. 556433, 1:500) monoclonal antibody was obtained from BD Biosciences (Franklin Lakes, NJ, USA). Bufalin was obtained from Sigma-Aldrich (St. Louis, MO, USA).

Cell cultures. The SGC7901, MGC803, BGC823 and MKN45 human gastric cancer cell lines were obtained from the Type Culture Collection of the Chinese Academy of Sciences (Shanghai, China). Cells were cultured in RPMI-1640 medium (Gibco Life Technologies, Grand Island, NY, USA) supplemented with $10 \%$ heat-inactivated fetal bovine serum (FBS), $100 \mathrm{U} / \mathrm{ml}$ penicillin and $100 \mathrm{mg} / \mathrm{ml}$ streptomycin at $37.0^{\circ} \mathrm{C}$ in $5 \% \mathrm{CO}_{2}$. Cells were subcultured for two to three days in order to maintain a log-phase growth for experiments.

Small interfering (si)RNA interference. SPARC and scrambled control siRNA were obtained from Shanghai GeneChem Co., Ltd. (Shanghai, China). The siRNA sequences used were as follows: Forward: 5'-GCCACUUCUUUGCCACAAAT)-3' and reverse: 5'-TTTGTGGCAAAGAAGTGGC-3' for SPARC-specific siRNA; and forward:5'-UUCUCCGAACGUGUCACGUTT-3' and reverse: 5'-ACGUGACACGUUCGGAGAATT-3' for scrambled control siRNA. SGC7901 cells were seeded at $2.5 \times 10^{5} /$ well into 6 -well plates and transfected with $5 \mu \mathrm{l} /$ well Lipofectamine 2000 (Invitrogen, Carlsbad, CA, USA) according to the manufacturer's instructions.

Cytotoxicity assays. Cell viability was measured using the 3-(4,5-dimethyl thiazol-2-yl)-2,5-diphenyl tetrazolium bromide (MTT) assay. SGC7901 cells were transfected with SPARC-specific or scrambled control siRNA following $30 \mathrm{~h}$ culture in a 6 -well plate, seeded into a 96 -well plate at a cell density of 5,000 per well and incubated overnight. Cell cultures, including the initial SGC7901 and MGC803 cells and the transfected SGC7901 cells were treated with varying concentrations of bufalin $(20,40,80,160,320 \mathrm{nmol} / \mathrm{l})$ for $20 \mathrm{~h}$ and $20 \mu \mathrm{l}$ of $5 \mathrm{mg} / \mathrm{ml} \mathrm{MTT}$ solution (Sigma-Aldrich) was added to each well, prior to incubation for a further $4 \mathrm{~h}$ at $37.0^{\circ} \mathrm{C}$. Following removal of the culture medium, cells were lysed in $200 \mu \mathrm{l}$ dimethylsulfoxide, and the optical density (OD) was measured at $570 \mathrm{~nm}$ using a microplate reader (Bio-Rad, Hercules, CA, USA). The following formula was used to calculate cell viability: Cell viability $(\%)=(\mathrm{OD}$ of the experimental sample/OD of the control group) x 100.

Cell cycle phase and mitochondrial membrane potential analysis. Phase distributions of the cell cycle and cell apoptosis were determined by flow cytometry. Cells were seeded at $2.5 \times 10^{5} /$ well in 6-well plates and transfected with SPARC siRNA or scrambled control siRNA at $30 \mathrm{~h}$. They were then exposed to bufalin (100 and $200 \mathrm{nmol} / 1$ doses) and incubated for 6 and $24 \mathrm{~h}$ in separate plates. Cells were trypsinized, washed once with phosphate-buffered saline (PBS) and then fixed with cold $70 \%$ ethanol overnight. Fixed cells were washed twice with PBS, incubated with $20 \mu \mathrm{g} / \mathrm{ml}$ ribonuclease A (RNase A) at $37.0^{\circ} \mathrm{C}$ for $30 \mathrm{~min}$ and stained with $10 \mu \mathrm{g} / \mathrm{ml}$ propidium iodide for $30 \mathrm{~min}$ in darkness. In addition to this, the mitochondrial membrane potential was determined by means of the cationic lipophilic fluorochrome DIOC6. Cells were collected and incubated with $20 \mathrm{~nm}$ DIOC6 (Molecular Probes Life Technologies, Carlsbad, CA, USA) for $15 \mathrm{~min}$ in darkness. The fluorescence intensity of the cells was detected using a BD FACSCalibur cytometer (BD Biosciences, San Jose, CA, USA) and the cell cycle distribution was analyzed using WinMDI 2.9 software (Scripps Research Institute, La Jolla, CA, USA).

Western blot analysis. Following administration of treatments at the time points indicated, the cells were washed twice with ice-cold PBS, lysed in 1\% Triton lysis buffer on ice and quantified using the Lowry method (27). Proteins $(40 \mu \mathrm{g})$ were separated using a 10\% SDS-polyacrylamide gel and transferred electrophoretically onto polyvinylidene difluoride membranes (Millipore, Bedford, MA, USA). The membranes were blocked with $5 \%$ non-fat milk in Tris-buffered saline with Tween-20 for $1.5 \mathrm{~h}$ at room temperature, and subsequently incubated with primary antibodies targeting SPARC, Caspase-3, PARP, Bax, Bcl-2, cytochrome $c$, Cyclin B1, Cyclin A, Cyclin E, Cdk2, p-AKT, p-ERK, p-Src, AKT, ERK and $\mathrm{Src}$, at $4^{\circ} \mathrm{C}$ overnight, prior to incubation with horseradish peroxidase-conjugated anti-rabbit (cat. no. sc-2491; 1:2,000) or mouse (cat. no. sc-2072; 1:2,000) secondary antibody (Santa Cruz Biotechnology, Inc.) for $1 \mathrm{~h}$ at room temperature. Protein bands were visualized with an enhanced chemiluminescence reagent (Super Signal Western Pico Chemiluminescence substrate, Pierce Biotechnology Inc., Rockford, IL, USA).

Statistical analysis. Data are presented as the mean \pm standard deviation. The significance of any differences between the groups was assessed by Student's t-test. Statistical analyses were performed using SPSS version 16.0 (SPSS Inc., Chicago, IL, USA). $\mathrm{P}<0.05$ was considered to indicate a statistically significant difference. All means were calculated from at least three independent experiments.

\section{Results}

SPARC reduces the sensitivity of gastric cancercells to bufalin. SPARC expression was measured in four gastric cancer cell lines. SGC7901 cells expressed the highest levels of SPARC, whilst the MGC803, BGC823 and MKN45 cell lines had markedly lower levels of expression (Fig. 1A). SGC7901 cells 
A

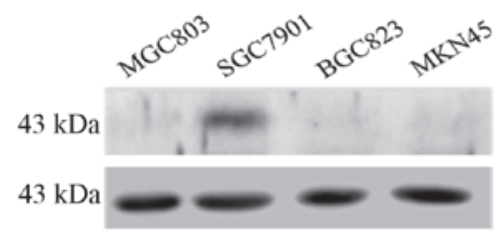

SPARC

Actin
B

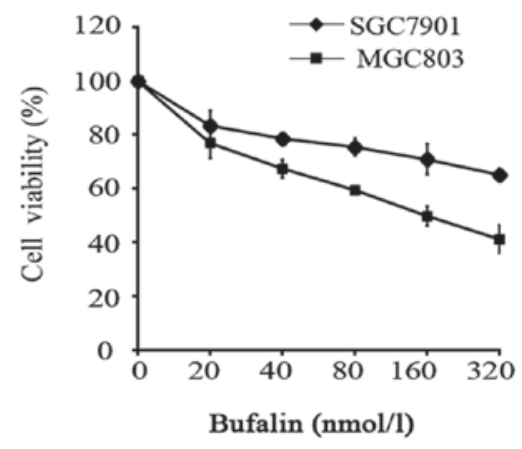

CTRL

C

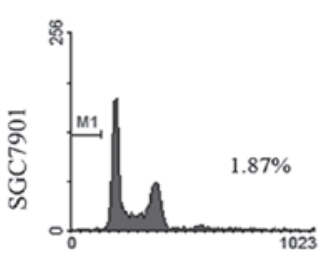

Bufalin (100nmol/1)
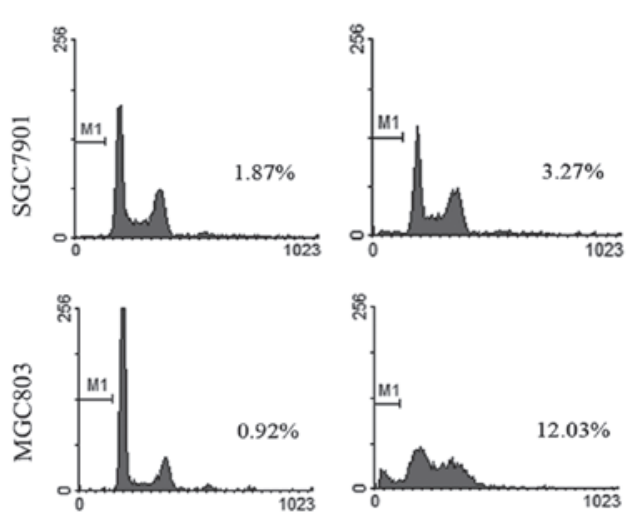

Bufalin(200nmol/1)
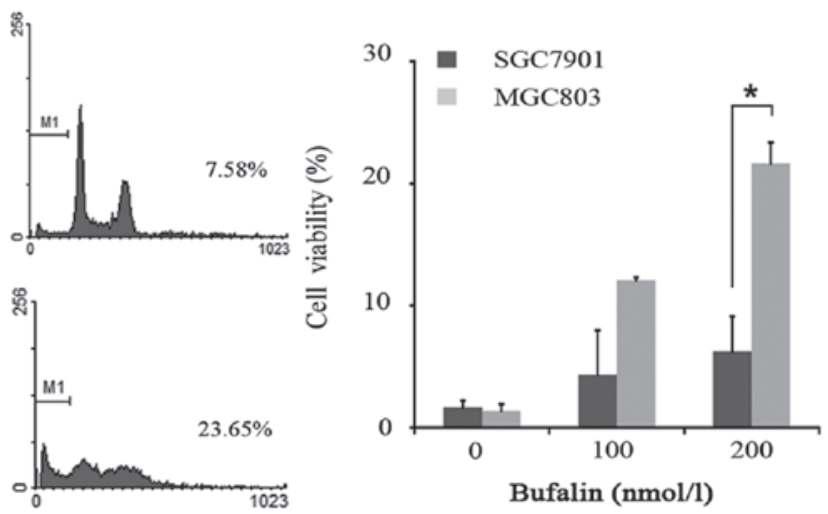

D
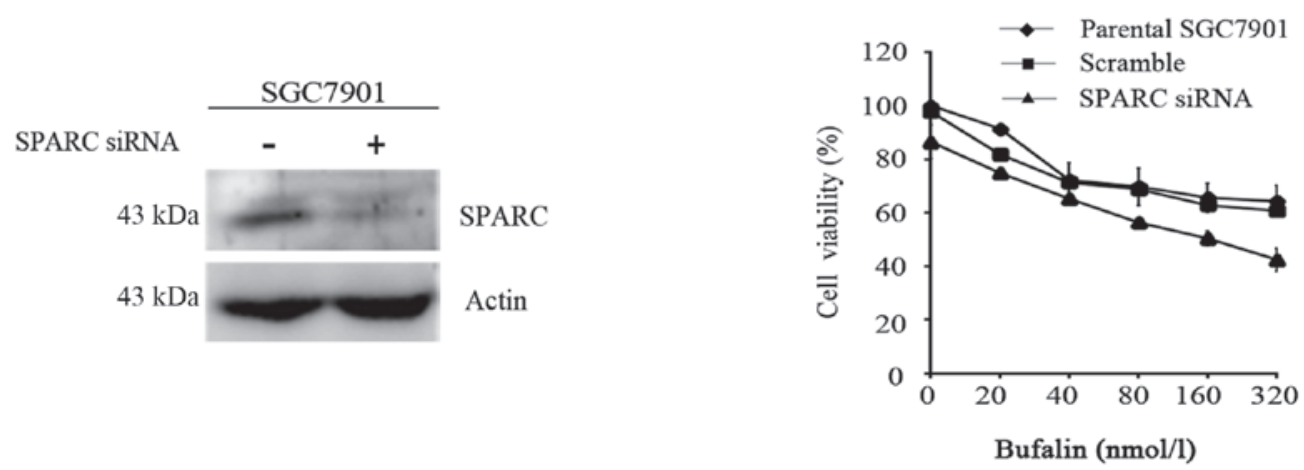

$\mathbf{E}$
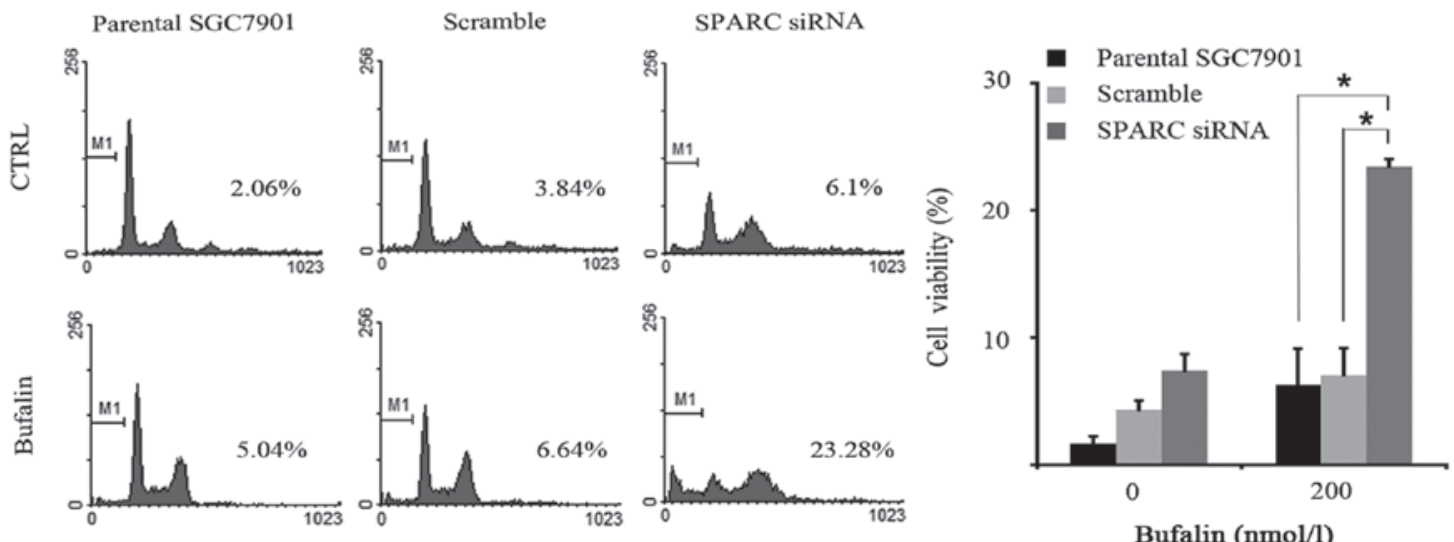

Figure 1. Effect of SPARC expression on the sensitivity of gastric cancer cells to bufalin. (A) SPARC expression was measured in four gastric cancer cell lines. Lane 1, MGC803; lane 2, SGC7901; lane 3, BGC823; lane 4, MKN45. Immunoblotting was conducted using a rabbit polyclonal SPARC antibody (1:200). (B) Viability of MGC803 and SGC7901 cell lines treated with varying concentrations of bufalin (20, 40, 80, 160 and $320 \mathrm{nmol} / \mathrm{l})$ for $24 \mathrm{~h}$ was assessed via an MTT assay. (C) Following incubation with bufalin (100 and $200 \mathrm{nmol} / \mathrm{l})$ for $24 \mathrm{~h}$, cell apoptosis as a sub-G1 fraction of SGC7901 and MGC803 cells was analyzed by flow cytometry. Cells were stained with propidium iodide. (D) Parental SGC7901 cells were transfected with SPARC-specific or scrambled control siRNA for $30 \mathrm{~h}$, and then treated with bufalin (20-320 nmol/l) for $24 \mathrm{~h}$. The cell viability was examined using an MTT assay. (E) Apoptosis of the cells as described in (D) was assessed by flow cytometry after treatment with or without $200 \mathrm{nmol} / \mathrm{l}$ bufalin at the indicated time-points (24 h). Columns indicate the mean percentage of apoptotic cells and bars indicate standard deviation. ${ }^{*} \mathrm{P}<0.05$. SPARC, secreted protein acidic and rich in cysteine; MTT, 3-(4,5-dimethyl thiazol-2-yl)-2,5-diphenyl tetrazolium bromide assay; siRNA, small interfering RNA. 
A

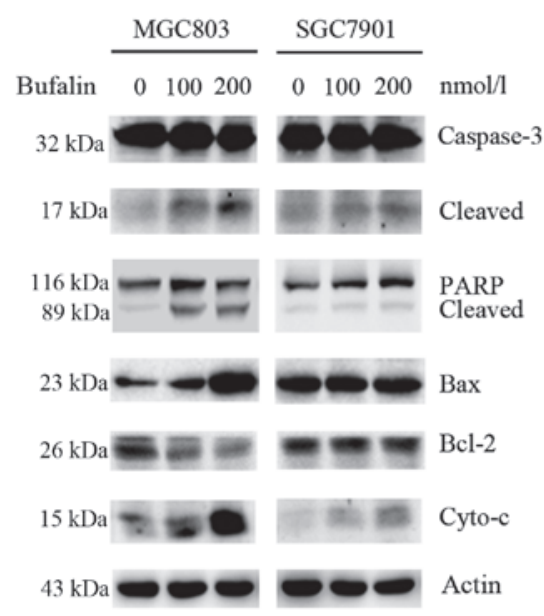

C

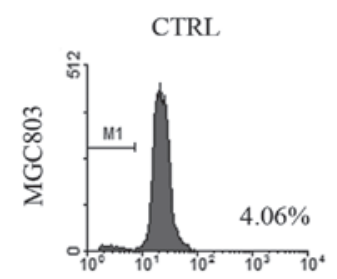

CTRL

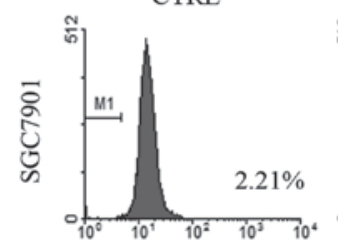

Bufalin

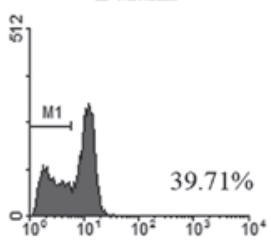

Bufalin

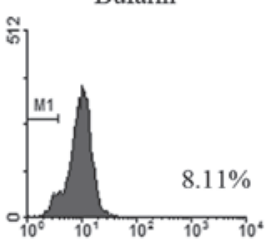

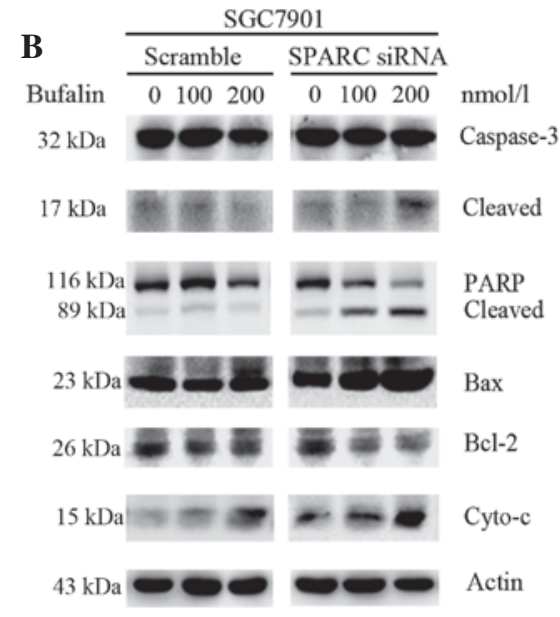

D
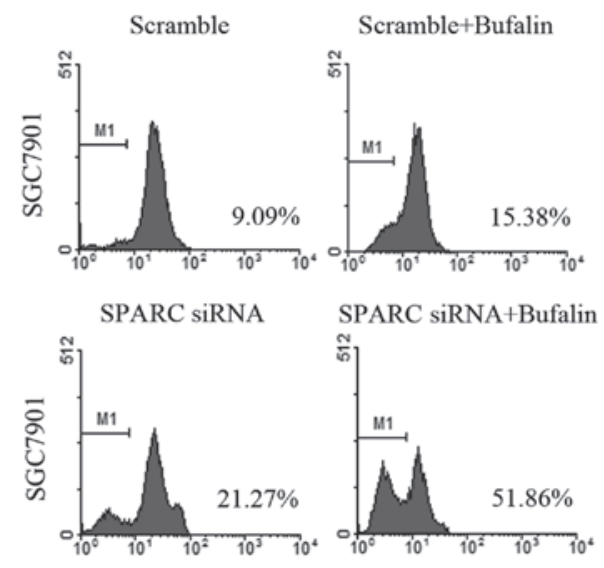

Figure 2. Effect of SPARC expression on bufalin-induced activation of intrinsic apoptosis. (A) Immunoblot showing the expression of proteins involved in the intrinsic apoptosis pathway in SGC7901 and MGC803 cells treated with bufalin (100 or $200 \mathrm{nmol} / \mathrm{l})$ for $24 \mathrm{~h}$. (B) Immunoblot showing the expression of proteins involved in apoptosis in parental SGC7901 cells or SGC7901 cells transfected with SPARC-specific or scrambled control siRNA for 30 h and treated with bufalin (100 and $200 \mathrm{nmol} / \mathrm{l}$ doses) for $24 \mathrm{~h}$. Analysis of cleavage of Caspase-3 and PARP, activation of the mitochondrial-associated proteins, Bax and Bcl-2, and release of cytochrome $c$ was also performed in each group of cells. (C) Mitochondrial membrane potentials of SGC7901 and MGC803 cells with and without bufalin treatment and (D) Mitochondrial membrane potentials of SGC7901 cells transfected with scrambled control or SPARC-specific riRNA and treated with bufalin were assessed by flow cytometry following staining with DiOC6. Actin was used as the internal control. SPARC, secreted protein acidic and rich in cysteine; PARP, poly (ADP-ribose) polymerase; cyto-c, cytochrome $c$; siRNA, small interfering RNA.

(high SPARC expression) and MGC803 cells (low SPARC expression) were selected for the following experiments. The viability of MGC803 and SGC7901 cell lines treated with varying concentrations of bufalin was assessed via an MTT assay. The $\mathrm{IC}_{50}$ value for the viability of SGC7901 cells treated with bufalin was $>800 \mathrm{nmol} / 1$ following $24 \mathrm{~h}$ treatment. This is approximately a 5-fold increase compared with the $\mathrm{IC}_{50}$ value of $160 \pm 0.87 \mathrm{nmol} / 1$ for the viability of MGC803 cells treated under the same conditions $(\mathrm{P}<0.001$; Fig. 1B). Flow cytometric analysis showed that $200 \mathrm{nmol} / \mathrm{l}$ bufalin induced apoptosis in $21.63 \pm 1.76 \%$ of MGC803 cells at $24 \mathrm{~h}$ compared with $6.027 \pm 2.85 \%$ of SGC7901 cells ( $<<0.001$; Fig. 1C). To further investigate whether SPARC influences the sensitivity of gastric cancer cells to bufalin, SGC7901 cells were transfected with SPARC-specific or scrambled control siRNA and treated with varying concentrations of bufalin over $24 \mathrm{~h}$. Compared with parental SGC7901 cells and scrambled siRNA control cells, knockdown of SPARC significantly decreased the $\mathrm{IC}_{50}$ value of cell viability following treatment with bufalin from 919.6 \pm 2.928 to $159.1 \pm 1.598 \mathrm{nmol} / 1$ ( $\mathrm{P}<0.001$; Fig. 1D). Consistent with this, the degree of bufalin-induced apoptosis in these cells also significantly increased, from 7.02 \pm 2.12 to $23.42 \pm 0.60 \%(\mathrm{P}<0.001$; Fig. 1E). These results suggest that higher levels of SPARC reduced the sensitivity of gastric cancer cells to bufalin treatment.

SPARC suppresses bufalin-induced activation of the intrinsic apoptosis pathway. To further investigate the effect of SPARC on bufalin-induced apoptosis in gastric cancer cells, the activation of apoptosis-related proteins was measured by western blot analysis. SGC7901 cells with high SPARC expression and MGC803 cells with low SPARC expression were treated with bufalin (100 and $200 \mathrm{nmol} / \mathrm{l}$ doses) for $24 \mathrm{~h}$. In MGC803 cells bufalin treatment markedly increased cleavage of Caspase- 3 and PARP, the release of cytoplasmic cytochrome $c$ and the ratio of $\mathrm{Bax} / \mathrm{Bcl}-2$. Minimal or no change in the levels of these proteins was observed in SGC7901 cells (Fig. 2A). SGC7901 cells transfected with SPARC or scrambled control 
A

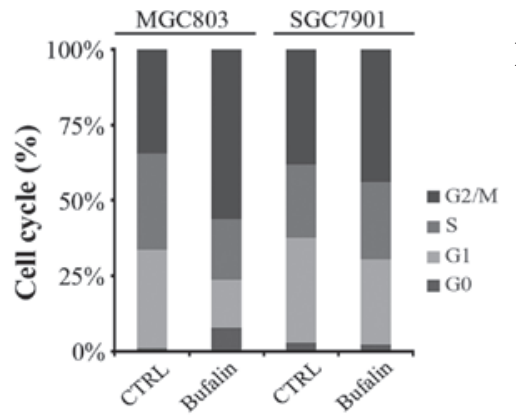

C

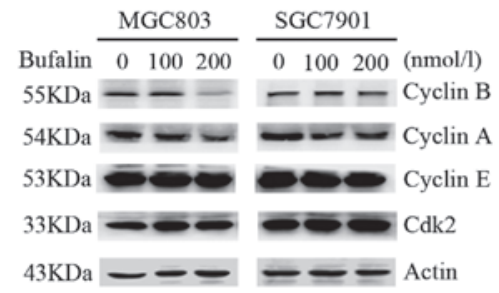

B

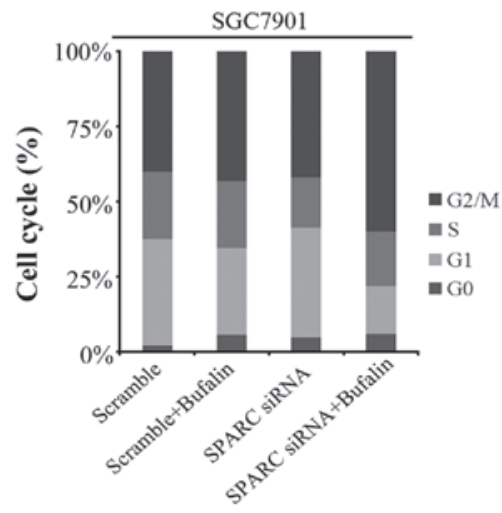

D

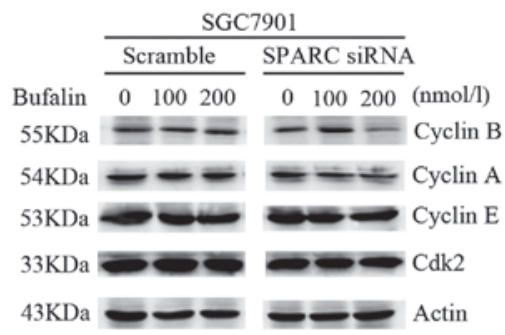

Figure 3. Effect of SPARC expression on bufalin-induced cell cycle arrest at G2/M phase. (A) SGC7901 and MGC803 cells, and (B) parental SGC7901 cells and SGC7901 cell transfected with SPARC-specific or scrambled control siRNA for $30 \mathrm{~h}$ were treated with bufalin (100 or $200 \mathrm{nmol} / \mathrm{l})$ for $6 \mathrm{~h}$. Following the incubation period, cell cycle stage was analyzed using flow cytometry with propidium iodide staining. The proportion of cells at each phase of the cycle are shown. (C) The cycle-related proteins (Cyclin B1, Cyclin A, Cyclin E and cdk2) of the cell groups from (A) and (D) the cycle-related proteins of the cell groups (B), were measured by western blot analysis. SPARC, secreted protein acidic and rich in cysteine; siRNA, small interfering RNA; cdk2, cyclin-dependent kinase 2 .

A

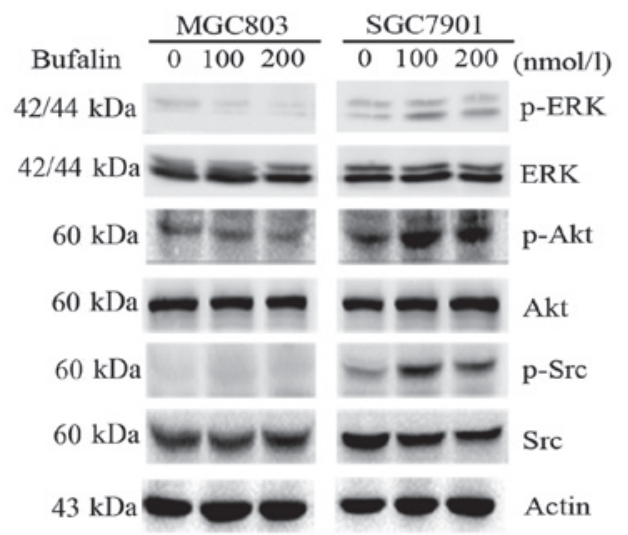

B

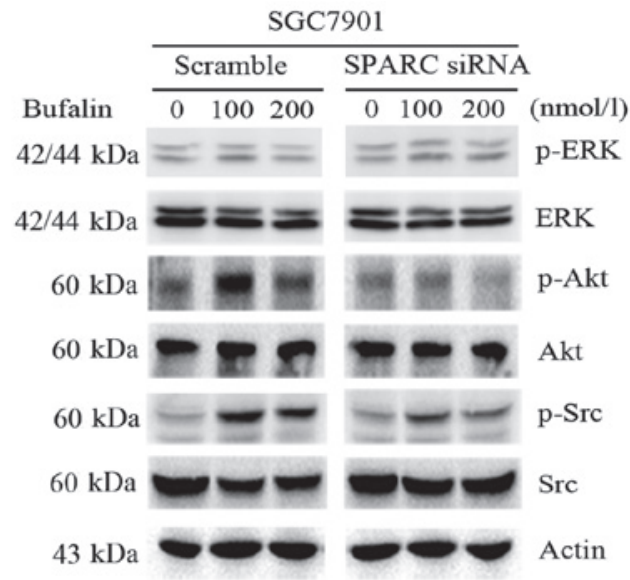

Figure 4. Effect of SPARC on the activation of survival signal pathways in bufalin-resistant gastric cancer cells. (A) Immunoblot showing expression of proteins involved in survival signal pathways in SGC7901 and MGC803 cells that had been treated with bufalin (100 and $200 \mathrm{nmol} / \mathrm{l})$ for $24 \mathrm{~h}$. (B) Immunoblot showing expression of proteins involved in survival signal pathways in parental SGC7901 cells and SGC7901 cells transfected with SPARC-specific and scrambled control siRNA which had been treated with bufalin. SPARC, secreted protein acidic and rich in cysteine; ERK, extracellular signal-regulated kinase; p-, phosphorylated; siRNA, small interfering RNA.

siRNA were then treated with bufalin at the doses and times indicated in Fig. 2B. Activation of mitochondrial-associated proteins, cytochrome $c$ and Bax, was significantly increased in SPARC-knockdown cells (Fig. 2B), as determined using ImageJ software. Furthermore, flow cytometry was conducted to measure the mitochondrial membrane potential $(\Delta \psi \mathrm{M})$ in these cells. Treatment of MGC803 cells with bufalin $(200 \mathrm{nmol} / \mathrm{l})$ for $24 \mathrm{~h}$ reduced $\Delta \psi \mathrm{M}$ to a greater degree than with bufalin treatment of SGC7901 cells (Fig. 2C). However, knockdown of SPARC significantly reduced $\Delta \psi \mathrm{M}$ in
SGC7901 cells treated with bufalin (Fig. 2D). These findings suggest that SPARC antagonizes bufalin-induced apoptosis through suppression of the intrinsic apoptotic pathway.

SPARC expression overcomes bufalin-induced cell cycle arrest at G2/M phase. In order to examine whether SPARC affects bufalin-induced cell cycle arrest in gastric cancer cell lines, MGC803 and SGC7901 cells were incubated with 100 or $200 \mathrm{nmol} / \mathrm{l}$ bufalin for $6 \mathrm{~h}$. Flow cytometry was conducted to assess the cell cycle state of these cells. The percentage of cells 
in $\mathrm{G} 2 / \mathrm{M}$ phase increased from 34.59 to $56.16 \%$ in MGC803 cells treated with $200 \mathrm{nmol} / \mathrm{l}$ bufalin, while a smaller increase from 38.19 to $44.05 \%$ was observed in SGC7901 cells (Fig. 3A). In accordance with prior results in this study, knockdown of SPARC in SGC7901 cells followed by exposure to $200 \mathrm{nmol} / \mathrm{l}$ bufalin for $6 \mathrm{~h}$ resulted in a greater number of cells arresting in G2/M phase compared with cells transfected with scrambled control siRNA $(60.07 \%$ and $43.19 \%$, respectively; Fig. 3B). The expression levels of the cell cycle-related proteins Cyclin B1, Cyclin A, Cyclin E and cdk2 were also measured. Levels of Cyclin B1 and Cyclin A were reduced in MGC803 cells and SGC7901 cells with knockdown of SPARC, compared with parental SGC7901 cells (Fig. 3C and D). These results indicate that SPARC expression overcomes bufalin-induced cell cycle arrest at the $\mathrm{G} 2 / \mathrm{M}$ phase.

SPARC enhances the activation of survival signal pathways in bufalin-resistant gastric cancer cells. To investigate whether SPARC influenced survival signaling pathways during treatment of MGC803 and SGC7901 cells with bufalin, the phosphorylation of Src, Akt and ERK was assessed. The degree of phosphorylation of Src, Akt and ERK was markedly increased in SGC7901 cells treated with bufalin alone (100 and $200 \mathrm{nmol} / \mathrm{l})$. By contrast, in MGC803 cells Akt phosphorylation did not visibly change (Fig. 4A). Notably, knockdown of SPARC in SGC7901 cells greatly suppressed activation of Src and Akt, but not ERK, when compared with cells transfected with scrambled control siRNA (Fig. 4B). These results suggest that SPARC enhances the activation of survival signal pathways in bufalin-resistant gastric cancer cells.

\section{Discussion}

Extracellular SPARC has received marked attention in cancer research due to its high affinity for albumin, which facilitates the targeting of nanoparticle albumin-bound drugs to tumor cells (17-20). Recently there has been an increased focus on the influence of intracellular levels of SPARC on the sensitivity of tumor cells to drugs (28-30). To the best of our knowledge, the present study demonstrates for the first time that SPARC suppresses bufalin-induced intrinsic apoptosis signals and G2/M cell cycle arrest, whilst concurrently promoting the activation of survival signaling pathways.

Previous reports concerning apoptosis regulation by SPARC are contradictory. One study found that SPARC promoted activation of the intrinsic apoptosis pathway via $\mathrm{Bid}$, and decreased the ratio of $\mathrm{Bcl}-2$ and Bax in colorectal cancer cells (30). However, SPARC has also been shown to protect against tyrosine kinase inhibitor-mediated apoptosis of chronic myeloid leukemia cells and to suppress the mitochondrial pathway in two human melanoma cell lines $(26,28)$ To date, to the best of our knowledge, there is no data regarding the influence of SPARC on bufalin-induced apoptosis. In this study, MGC803 and SGC7901 gastric cancer cells exhibited different sensitivities to bufalin, and the level of expression of SPARC was negatively correlated with this sensitivity. It has been reported that the Fas/Fas ligand pathway and the mitochondrial pathway are involved in bufalin-triggered apoptosis (8). The current study demonstrated that bufalin-resistant SGC7901 cells with high SPARC expression had reduced mitochondrial integrity, reduced release of cytoplasmic cytochrome $c$ and an increased Bcl-2:Bax ratio. Additionally, knockdown of SPARC restored bufalin-induced apoptosis. These findings suggest that SPARC may be crucial in resisting bufalin-induced apoptosis in gastric cancer.

Bufalin treatment led to the arrest of hepatocellularcarcinoma cells in G2/M phase as a result of modulation of Cyclin B1 (6). Tumor cell-derived SPARC may bypass the G2/M checkpoint, thereby facilitating loss of control of the cell cycle, by reducing expression of Cyclin B1 in melanoma (31). In the present study, it was observed that low SPARC expression was associated with a greater percentage of cells in G2/M phase following bufalin treatment. Consistent with this, knockdown of SPARC led to an increase in G2/M arrest in SGC7901 cells treated with bufalin. In addition, expression of Cyclin B1 and Cyclin A, but not cdk2 and Cyclin E, decreased following silencing of SPARC. These results indicate that SPARC overcomes bufalin-induced G2/M arrest via regulation of the expression of Cyclin proteins.

Several reports have indicated that inhibition of certain tumor cell survival pathways, including the PI3K and mitogen-activated protein kinase pathways, enhances bufalin-induced apoptosis $(32,33)$. Furthermore, activity of Akt was shown to be increased in bufalin-insensitive hepatocellular carcinoma cells (34). Bufalin has also been shown to act synergistically with Akt inhibitors to enhance apoptosis in lung cancer cells (33). SPARC was demonstrated to significantly suppress activation of Akt in hepatic and ovarian carcinoma $(35,36)$. However, SPARC has also been reported to reduce tumor cell apoptosis and promote tumor cell survival by upregulating p-Akt in malignant glioma and melanoma $(23,37)$. In this study, it was observed that Akt pathways, but not ERK pathways, were markedly activated in gastric cancer cells with high levels of expression of SPARC. By contrast, the degree of Akt phosphorylation was lower in gastric cancer cells with low levels of SPARC expression. Notably, increased Src phosphorylation was also observed in SGC7901 gastric cancer cells with high levels of SPARC. It was also observed that knockdown of SPARC in SGC7901 cells inhibited bufalin-induced Src phosphorylation. An earlier study showed that SPARC inhibits cellular migration and invasion via the activation of Src in medulloblastoma cells (38). However, there have been no reports on the effect of the association between SPARC and Src on drug sensitivity in tumor cells. The results presented in the current study indicate that SPARC is involved in gastric cancer cell resistance to bufalin via activation of the Akt and Src pathways.

This study demonstrates that SPARC protects against bufalin-induced apoptosis in gastric cancer cells. This is achieved by inhibition of the mitochondrial apoptosis pathway, including downregulation of the release of cytoplasmic cytochrome $c$, upregulation of the Bcl-2:Bax ratio, inhibition of cell cycle arrest and activation of Src and Akt. Targeting SPARC expression may prove useful in the development of novel individualized therapeutic strategies to enable the effective use of bufalin in gastric cancer.

\section{Acknowledgements}

This study was supported by grants from the National Natural Science Foundation of China (grant nos. 81172369, 81372485 
and 81372547) and the National Science and Technology Major Project of the Ministry of Science and Technology of China (grant no. 2013ZX09303002).

\section{References}

1. Kanat $\mathrm{O}$ and $\mathrm{O}^{\prime} \mathrm{Neil} \mathrm{BH}$ : Metastatic gastric cancer treatment: a little slow but worthy progress. Med Oncol 30: 464, 2013.

2. Hong Z, Chan K and Yeung HW: Simultaneous determination of bufadienolides in the traditional Chinese medicine preparation, liu-shen-wan, by liquid chromatography. J Pharm Pharmacol 44 1023-1026, 1992.

3. Panesar NS: Bufalin radioimmunoassays: in search of the endogenous digitalis-like substance. J Immunoassay 15: 371-391, 1994

4. Kang XH, Xu ZY, Gong YB, et al: Bufalin reverses HGF-induced resistance to EGFR-TKIs in EGFR mutant lung cancer cells via blockage of Met/PI3k/Akt pathway and induction of apoptosis. Evid Based Complement Alternat Med 2013: 243859, 2013.

5. Yan S, Qu X, Xu C, et al: Down-regulation of Cbl-b by bufalin results in up-regulation of DR4/DR5 and sensitization of TRAIL-induced apoptosis in breast cancer cells. J Cancer Res Clin Oncol 138: 1279-1289, 2012.

6. Zhang DM, Liu JS, Tang MK, et al: Bufotalin from Venenum Bufonis inhibits growth of multidrug resistant HepG2 cells through G2/M cell cycle arrest and apoptosis. Eur J Pharmacol 692: 19-28, 2012.

7. Watabe M, Ito K, Masuda Y, Nakajo S and Nakaya K: Activation of AP-1 is required for bufalin-induced apoptosis in human leukemia U937 cells. Oncogene 16: 779-787, 1998.

8. Qi F, Inagaki Y, Gao B, et al: Bufalin and cinobufagin induce apoptosis of human hepatocellular carcinoma cells via Fas- and mitochondria-mediated pathways. Cancer Sci 102: 951-958, 2011

9. Hsiao YP, Yu CS, Yu CC, et al: Triggering apoptotic death of human malignant melanoma a375.s2 cells by bufalin: involvement of caspase cascade-dependent and independent mitochondrial signaling pathways. Evid Based Complement Alternat Med 2012: 591241, 2012.

10. Huang WW, Yang JS, Pai SJ, et al: Bufalin induces $\mathrm{G}(0) / \mathrm{G}(1)$ phase arrest through inhibiting the levels of cyclin $\mathrm{D}$, cyclin $\mathrm{E}$, CDK2 and CDK4, and triggers apoptosis via mitochondrial signaling pathway in T24 human bladder cancer cells. Mutat Res 732: 26-33, 2012.

11. Li D, Qu X, Hou K, et al: PI3K/Akt is involved in bufalin-induced apoptosis in gastric cancer cells. Anticancer Drugs 20 : 59-64, 2009

12. Yan Q and Sage EH: SPARC, a matricellular glycoprotein with important biological functions. J Histochem Cytochem 47: 1495-1506, 1999.

13. Seux M, Peuget S, Montero MP, et al: TP53INP1 decreases pancreatic cancer cell migration by regulating SPARC expression. Oncogene 30: 3049-3061, 2011.

14. Azim HA Jr, Singhal S, Ignatiadis M, et al: Association between SPARC mRNA expression, prognosis and response to neoadjuvant chemotherapy in early breast cancer: a pooled in-silico analysis. PLoS One 8: e62451, 2013.

15. Shin M, Mizokami A, Kim J,et al: Exogenous SPARC suppresses proliferation and migration of prostate cancer by interacting with integrin $\beta 1$. Prostate 73: 1159-1170, 2013.

16. Yin J, Chen G, Liu Y, et al: Downregulation of SPARC expression decreases gastric cancer cellular invasion and survival. J Exp Clin Cancer Res 29: 59, 2010.

17. Desai N, Trieu V, Damascelli B and Soon-Shiong P: SPARC expression correlates with tumor response to albumin-bound paclitaxel in head and neck cancer patients. Transl Oncol 2: 59-64, 2009.
18. Von Hoff DD, Ramanathan RK, Borad MJ, et al: Gemcitabine plus nab-paclitaxel is an active regimen in patients with advanced pancreatic cancer: a phase I/II trial. J Clin Oncol 29: 4548-4554, 2011.

19. Demeure MJ, Stephan E, Sinari S, et al: Preclinical investigation of nanoparticle albumin-bound paclitaxel as a potential treatment for adrenocortical cancer. Ann Surg 255: 140-146, 2012.

20. Guarneri V, Dieci MV and Conte P: Enhancing intracellular taxane delivery: current role and perspectives of nanoparticle albumin-bound paclitaxel in the treatment of advanced breast cancer. Expert Opin Pharmacother 13: 395-406, 2012.

21. Chen J, Shi D, Liu X, Fang S, Zhang J and Zhao Y: Targeting SPARC by lentivirus-mediated RNA interference inhibits cervical cancer cell growth and metastasis. BMC Cancer 12: 464, 2012.

22. Chen J, Wang M, Xi B, et al: SPARC is a key regulator of proliferation, apoptosis and invasion in human ovarian cancer. PLoS One 7: e42413, 2012.

23. Fenouille N, Puissant A, Tichet M, et al: SPARC functions as an anti-stress factor by inactivating p53 through Akt-mediated MDM2 phosphorylation to promote melanoma cell survival. Oncogene 30: 4887-4900, 2011.

24. Gorantla B, Bhoopathi P, Chetty C, et al: Notch signaling regulates tumor-induced angiogenesis in SPARC-overexpressed neuroblastoma. Angiogenesis 16: 85-100, 2013.

25. Seno T, Harada H, Kohno S, Teraoka M, Inoue A and Ohnishi T. Downregulation of SPARC expression inhibits cell migration and invasion in malignant gliomas. Int J Oncol 34: 707-715, 2009.

26. Horie K, Tsuchihara M, Nakatsura T: Silencing of secreted protein acidic and rich in cysteine inhibits the growth of human melanoma cells with G arrest induction. Cancer Sci 101: 913-919, 2010.

27. Sengupta S and Chattopadhyay MK: Lowry's method of protein estimation: Some more insights. J Pharm Pharmacol 45: 80, 1993.

28. Giallongo C, La Cava P, Tibullo D, et al: SPARC expression in CML is associated to imatinib treatment and to inhibition of leukemia cell proliferation. BMC Cancer 13: 60, 2013.

29. Schultz CR, Golembieski WA, King DA, Brown SL, Brodie C and Rempel SA: Inhibition of HSP27 alone or in combination with pAKT inhibition as therapeutic approaches to target SPARC-induced glioma cell survival. Mol Cancer 11: 20, 2012.

30. Rahman M, Chan AP and Tai IT: A peptide of SPARC interferes with the interaction between caspase 8 and $\mathrm{Bcl} 2$ to resensitize chemoresistant tumors and enhance their regression in vivo. PLoS One 6: e26390, 2011.

31. Fenouille N, Robert G, Tichet M, et al: The p53/p21Cip1/Waf1 pathway mediates the effects of SPARC on melanoma cell cycle progression. Pigment Cell Melanoma Res 24: 219-232, 2011.

32. Jiang Y, Zhang Y, Luan J, et al: Effects of bufalin on the proliferation of human lung cancer cells and its molecular mechanisms of action. Cytotechnology 62: 573-583, 2010.

33. Zhu Z, Sun H, Ma G, et al: Bufalin induces lung cancer cell apoptosis via the inhibition of PI3K/Akt pathway. Int J Mol Sci 13: 2025-2035, 2012.

34. Li H, Wang P, Gao Y, et al: $\mathrm{Na}^{+} / \mathrm{K}^{+}$-ATPase $\alpha 3$ mediates sensitivity of hepatocellular carcinoma cells to bufalin. Oncol Rep 25: 825-830, 2011.

35. Li Y, Chen L, Chan TH, et al: SPOCK1 is regulated by CHD1L and blocks apoptosis and promotes HCC cell invasiveness and metastasis in mice. Gastroenterology 144: 179-191, 2013.

36. Said N, Najwer I and Motamed K: Secreted protein acidic and rich in cysteine (SPARC) inhibits integrin-mediated adhesion and growth factor-dependent survival signaling in ovarian cancer. Am J Pathol 170: 1054-1063, 2007.

37. Liu H, Xu Y, Chen Y, et al: RNA interference against SPARC promotes the growth of U-87MG human malignant glioma cells. Oncol Lett 2: 985-990, 2011.

38. Bhoopathi P, Gondi CS, Gujrati M, Dinh DH and Lakka SS: SPARC mediates Src-induced disruption of actin cytoskeleton via inactivation of small GTPases Rho-Rac-Cdc42. Cell Signal 23: 1978-1987, 2011. 